\title{
Experimental Evaluation for the Catalytic Effect of Nickel in Micron Size on Magnesium Hydride
}

\author{
DWI RAHMALINA \\ Department Mechanical Engineering \\ Universitas Pancasila \\ Srengseng Sawah, Jagakarsa, Jakarta 12640 \\ INDONESIA \\ REZA ABDU RAHMAN \\ Department Mechanical Engineering \\ Universitas Pancasila \\ Srengseng Sawah, Jagakarsa, Jakarta 12640 \\ INDONESIA \\ ISMAIL \\ Department Mechanical Engineering \\ Universitas Pancasila \\ Srengseng Sawah, Jagakarsa, Jakarta 12640 \\ INDONESIA
}

\begin{abstract}
Magnesium hydride is well known as the ideal candidate for solid-state hydrogen storage and thermochemical thermal storage since both gravimetric and volumetric storage are considerably high. The main drawbacks of magnesium hydride are thermodynamic unfavorable and poor kinetic. Adding Nickel as a catalyst, which mainly incorporates mechanical modification (alloying or particle size reduction), can accelerate the reaction rate and decrease the enthalpy formation. It is hard to determine the catalytic of Nickel in magnesium hydride for the kinetic rate improvement. This study is focused on the observation of the effect of Nickel on magnesium hydride by using the market size availability of magnesium and nickel powder (74 $\mu \mathrm{m}$ for $\mathrm{Mg}$ and $63 \mu \mathrm{m}$ for $\mathrm{Ni}$ ). $\mathrm{Mg}$ and $\mathrm{Ni}$ are mixed by $\mathrm{Ni}$ variation (weight $\%$ ) from 14\%, 15\%, and 16\%. The characterization starts with initial hydrogenation and dehydrogenation, continues with activation and PCI measurement to obtain the kinetic characteristic of each sample. From this study, it is clear that the increase in nickel ratio will improve the rate of reaction for magnesium hydride, where the maximum storage for magnesium hydride is $4.2 \%$ by adding $16 \mathrm{wt} \%$ nickel.
\end{abstract}

Key-Words: - Catalytic Effect, Hydrogen Storage, Kinetic Rate, Magnesium Hydride, Nickel Catalyst

Received: April 30, 2021. Revised: October 19, 2021. Accepted: November 24, 2021. Published: December 27, 2021.

\section{Introduction}

Hydrogen has the highest chance and plays a critical role in renewable energy used as an energy carrier [1]. Vast availability and high energy density make hydrogen suitable for further improvement to achieve large scale implementation and shift from hydrocarbon society into hydrogen society [2]. Thermal energy storage in form as latent heat Latent thermal energy storage [3-5] can be maximized by combining the heat of reaction from hydrogen storage [6-8]. Also, hydrogen can help to maximizing the power generation for wind farm by using multi storage system between heat, electricity, hydrogen [9-11] and can be coupled with the design optimization for wind turbine $[12,13]$.

Hydrogen is mainly found as a molecule with some unfavorable properties due to high reactivity and less dense [14]. It makes hydrogen is impractical for long term and mobile storage neither through cryogenic storage nor high-pressure storage $[15,16]$. The alternative method to stored hydrogen in a relatively safe method is solid-state hydrogen storage through metal hydride. Hydrogen can react with metals and form metal hydride [17]. Storing hydrogen with metal hydride is much better in term of storage capacity. The average density for storing 
hydrogen in liquid and gas are $4.2 \mathrm{H}$ atoms $/ \mathrm{cm}^{3}$ and $0.99 \mathrm{H}$ atoms $/ \mathrm{cm}^{3}$, which is lower than storing hydrogen as solid-state with metal hydride, which can reach up to $6.5 \mathrm{H}$ atoms $/ \mathrm{cm}^{3}$ by using Magnesium to form stable magnesium hydride or $\mathrm{MgH}_{2}$ [18].

Hydrogen reacts with metal by splitting hydrogen molecule into atomic hydrogen, which bond with a metal lattice to form a metallic bond with the metal host. As the molecular hydrogen break the bond, the molecular bonding energy is released as heat through an exothermic reaction [19]. The excess heat from the reaction is also valuable, applied in a thermal system or better known as thermochemical heat storage. Under this circumstance, storing hydrogen in metal hydride has two significant benefits: solid-state hydrogen storage and thermal energy storage [20]. Many metals can react with hydrogen to form metal hydride [18,21,22]. Considering the economic aspect and storage capacity both in volumetric and gravimetric, Magnesium is the ideal candidate as the metal host for hydrogen storage [23]. Magnesium and hydrogen react to form stable magnesium hydride $\left(\mathrm{MgH}_{2}\right)$ with high enthalpy reaction or $\Delta \mathrm{H}$ around $-75 \mathrm{~kJ} / \mathrm{molH}_{2}$ with standard entropy or $\Delta \mathrm{S}$ 130 J.K..$\left(\mathrm{mol} \mathrm{H}_{2}\right)^{-1}$ [24].

The stored hydrogen in magnesium hydride can be desorbed by providing sufficient heat into the system. By making a close loop between the storage and a reservoir, the system can run as a cycle which able to use repeatedly. The system can be coupled with some thermal load for harvesting the enthalpy of reaction along the hydriding process [7]. Unfortunately, the high enthalpy of reaction indicates a stable form of magnesium hydride, which make high enough heat should be provided to desorb hydrogen for dehydriding. Another challenge is that magnesium hydride has a low kinetic reaction for hydrogenation and dehydrogenation [25].

One suitable method to eliminate the drawbacks of the magnesium hydride is by adding catalyst into the system. The ideal catalyst for magnesium hydride is nickel [26]. Nickel is proven to accelerate hydrogen sorption during hydriding and dehydriding. It makes the system's equilibrium pressure decrease and can reduce the enthalpy and entropy of the reaction. The catalytic effect of Nickel is worked by breaking the molecular hydrogen and adsorbing the atomic hydrogen onto the nickel surface, then dissociating Magnesium. Though Nickel can accelerate the kinetic rate of the magnesium hydride system, adding Nickel has a side effect that decreases the amount of stored hydrogen [27].
Numerous studies are done to minimizing the drawback of nickel addition against the decrease in hydrogen storage capacity for magnesium hydride. Mixing Magnesium through mechanical grinding with Nickel at different weight ratio (38 wt $\%$ and 43 $\mathrm{wt} \%$ ) reduces the enthalpy formation and equilibrium pressure of $\mathrm{H}_{2}$ with a maximum storage capacity of $3.6 \mathrm{wt} \%$ [28]. Another study report that mixing Nickel at a range of 1-33 wt \% through melt spinning can maximize the hydrogen uptake by 6 wt\% [29]. Another reportage is also confirmed that using the same ratio for Nickel (15 wt $\%)$ and combined with graphite $5 \mathrm{wt} \%$ and $1.5 \mathrm{wt} \% \mathrm{TiO}_{2}$ with pellet size can also improve the hydrogen storage capacity by $6 \mathrm{wt} \%$ [25]. The recent study shows a noticeable storage capacity of magnesium hydride system by adding $16 \mathrm{wt} \%$ Nickel without nanosizing where the maximum storage can reach up to $5.29 \% \mathrm{H}_{2}$ [30]. It can reach a sufficient amount of hydrogen storage as the effect of scaling during hydriding and dehydriding of the samples [31].

In general, most of the study for improving the magnesium hydride by nickel catalyst is done through surface modification, particularly for mechanical grinding for particle downsizing and mechanical alloying [32]. However, processing the material through mechanical modification and nanoconfinement makes it not economically feasible, delaying the implementation of magnesium hydride systems for large-scale applications. According to the recent studies of magnesium hydride, adding Nickel by $15 \mathrm{wt} \%$ shows a positive result for the magnesium hydride. Thus, this study aims to observe the catalytic effect of magnesium hydride by adding nickel $15 \mathrm{wt} \%$ using widely available market grade nickel. To provide a more indepth understanding of the result, the nickel addition varies by $\pm 1 \mathrm{wt} \%$. The result of the study is expected to provide better information about the nature of the catalytic effect from Nickel in magnesium hydride.

\section{Materials and Methods}

Three different samples from Magnesium (74 $\mu \mathrm{m}$, purity: 99.9\%, Tanyun Chemical Co., Ltd.) and Nickel $(63 \mu \mathrm{m}$, purity: 99.9\%, Tanyun Chemical Co., Ltd.) were prepared based on the mass ratio (Table 1). $\mathrm{Mg}$ and $\mathrm{Ni}$ were mixed carefully to ensure the homogeneity of the mixture. Each sample is mixed by using a ring mill for 5 minutes under an argon atmosphere. Stainless steel ball mill with a diameter of $5 \mathrm{~mm}$ is used with the ball to powder ratio of 20:1. Stearic acid (1 gram) was used to prevent agglomeration during the milling process 
and then removed after milling using a vacuum gas furnace. The materials handling and processing were handled in the glove box (argon gas) to eliminate the probability of oxide layer on the sample surface where it can hinder the sorption mechanism of the magnesium hydride [33]. Moisture test (Mettler Toledo) were done before and after milling and obtained average moisture of $0.23 \%$, which is considered acceptable [34].

After all sample ready, further characterization is conducted using Sievert Type Apparatus for volumetric measurement. The volumetric measurement is chosen as it has better accuracy and easy to use for large-scale experiments [35]. Using a large sample (100 grams) demanded proper calibration. Thus, the measurement of void volume for the sample holder and gas container is conducted repeatedly, including the instrumentation measurement.

Table 1. Prepared sample based on magnesium and nickel ratio

\begin{tabular}{ccc}
\hline Code & Magnesium $(\mathbf{w t} \%)$ & Nickel $(\mathbf{w t} \%)$ \\
\hline A & 86 & 14 \\
B & 85 & 15 \\
C & 84 & 16 \\
\hline
\end{tabular}

Hydrogenation and dehydrogenation are taken through a temperature-programmed method with a constant heating rate $(5 \mathrm{~K} / \mathrm{min})$ for stable convective heat transfer [36]. Each measurement is taken for two hours with the pressure for hydriding and dehydriding of $5 \mathrm{MPa}$ and $0.1 \mathrm{MPa}$, respectively. After that, the sample is prepared for PressureComposition-Isotherm (PCI) [37]. Before conducting PCI, the sample was activated five times by introducing hydrogen pressure of $5.01 \mathrm{MPa}$ at temperature $573 \mathrm{~K}$ then evacuated at $300 \mathrm{~K}$. The $\mathrm{PCI}$ is taken at $473 \mathrm{~K}, 523 \mathrm{~K}$, and $573 \mathrm{~K}$. PCI and activation were taken for two hours. The temperature for the PCI is selected by considering the ideal working temperature for sustainable hydrogen-producing and storage to improve the overall efficiency of the hydrogen processing plant [38].

\section{Results}

\subsection{Initial Dehydrogenation}

The initial hydrogenation test is aimed to study the basic hydriding characteristic for each sample. Figure 1 presents the amount of absorbed hydrogen from each sample during hydrogenation. Pure magnesium absorb hydrogen insufficiently where after two hours, it only absorbs by $0.21 \mathrm{wt} \% \mathrm{H}_{2}$ where sample with nickel addition able to absorb hydrogen at higher amount. The hydrogen content for sample with nickel addition (Sample A, B and C) are $0.29,0.45$ and $0.9 \mathrm{wt} \% \mathrm{H}_{2}$. It proves that nickel able to accelerate the hydrogen sorption for magnesium.

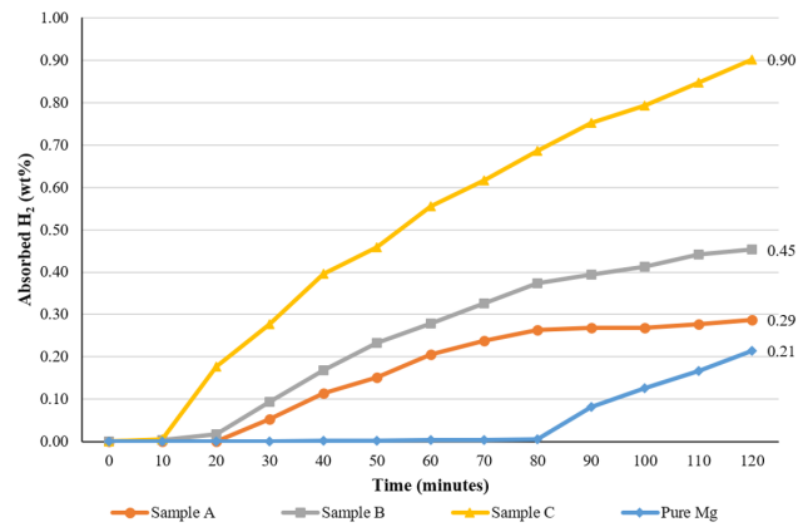

Fig. 1: Initial hydrogenation for each sample

The releasing hydrogen during dehydrogenation is shown in Figure 2. The same pattern for all samples is observed where magnesium shows a slower dehydrogenation and starts to desorb hydrogen after 60 minutes. Compare to the absorbed hydrogen from initial hydrogenation, the desorbed hydrogen for sample A and B is lower. Sample A and $\mathrm{B}$ only able to desorb hydrogen by -0.27 and $0.43 \mathrm{wt} \% \mathrm{H}_{2}$, respectively.

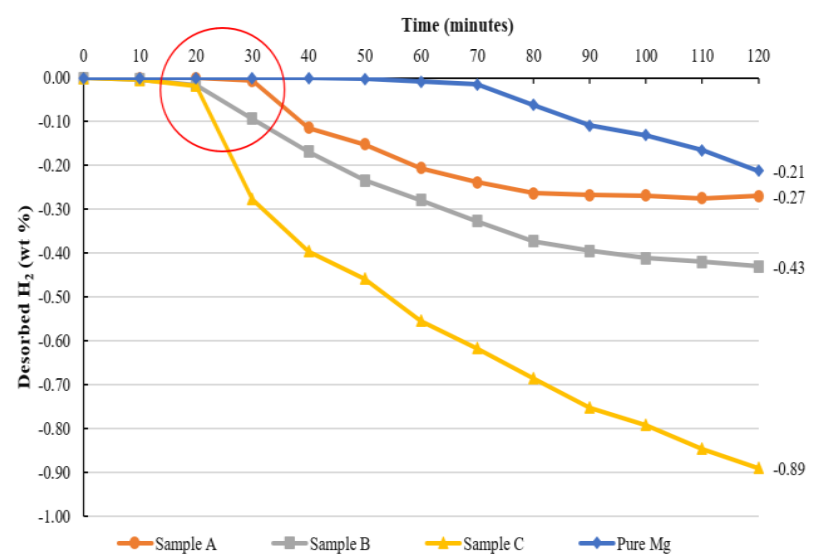

Fig. 2: Initial dehydrogenation for each sample

It shows that some of the hydrogen molecule cannot be desorbed. Sample C also presents the same result where the desorbed hydrogen is smaller with only $0.89 \mathrm{wt} \% \mathrm{H}_{2}$. Nevertheless, sample $\mathrm{C}$ able to release more hydrogen compare to sample A and B. Also, sample $\mathrm{C}$ has the highest stored hydrogen by 0.89 wt $\% \mathrm{H}_{2}$ can be stored effectively. 
The result of hydrogenation and dehydrogenation for magnesium hydride with Nickel as catalyst present the initial information for the kinetic rate reaction. Nickel plays a vital role to accelerate the hydrogen sorption for magnesium hydride. Magnesium is the metal host to react with hydrogen, while Nickel helps the formation and decomposition of the hydride. Dissociation of hydrogen molecule occurs with the help of strong affinity between hydrogen molecules and Nickel [39]. Thus, the information from initial hydrogenation and dehydrogenation should be supported by Pressure Composition Isotherm (PCI) to understand Nickel's effect on the equilibrium pressure of magnesium hydride.

\subsection{Cycle Activation}
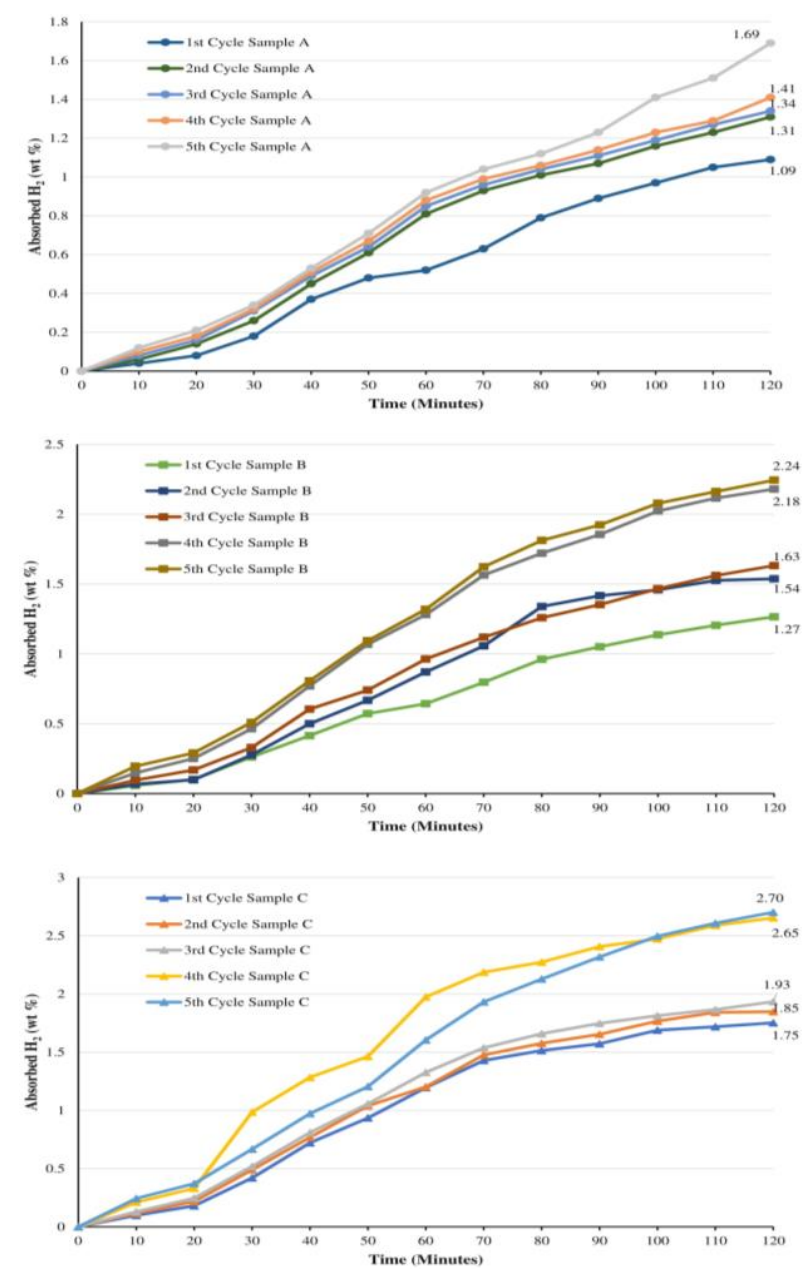

Fig. 3: Absorbed hydrogen for each sample from 5 times activation

Before conducting PCI measurement, the activation must be conducted to eliminate the oxide layer on the sample surface while also preparing the material to maximize the sorption during PCI. Besides, the result of activation itself is helpful to observe the cyclic ability of the material. The activation result for each sample is shown in Figure 3. At first cycle, sample A only able to desorb hydrogen by 1.09 wt $\%$. As the cycle increased up to five times, the maximum stored hydrogen is obtained at $1.69 \mathrm{wt} \%$, much lower compared to sample B and C. Sample able to achieves a higher stored hydrogen at first cycle by $1.27 \mathrm{wt} \%$ and after five cycles, the amount of stored hydrogen is obtained at $2.24 \mathrm{wt} \%$.

The highest stored hydrogen can be obtained by sample C with $16 \mathrm{wt} \%$ nickel. At first cycle, the absorbed hydrogen is $1.75 \mathrm{wt} \%$ and at the end of the fifth cycle, the stored hydrogen is increased up to $2.70 \mathrm{wt} \%$. During the first three cycle, the amount of absorbed hydrogen is relatively increased slowly, and after that, the hydrogen molecules able to absorb at higher rate. Each sample shows different cycle pattern which indicates the activation process should be done at first place to promote a better pathway for hydrogen to react with the metal host (magnesium). As the cycle increase, the pathway becomes clearer and help the hydrogen molecule to penetrate easier. Thus, it increases the sorption rate which elevates the amount of absorbed hydrogen to form magnesium hydride.

\subsection{Pressure-Composition-Isotherm}

Figure 4 presents the hydriding/dehydriding rate for sample A at different temperature. It is clear enough to say that the sorption rate for hydriding and dehydriding is prolonged. The critical sorption is reached after 60 mins. Critical sorption can be defined as more than $80 \%$ hydrogen is absorbed during hydriding or desorbed during dehydriding.

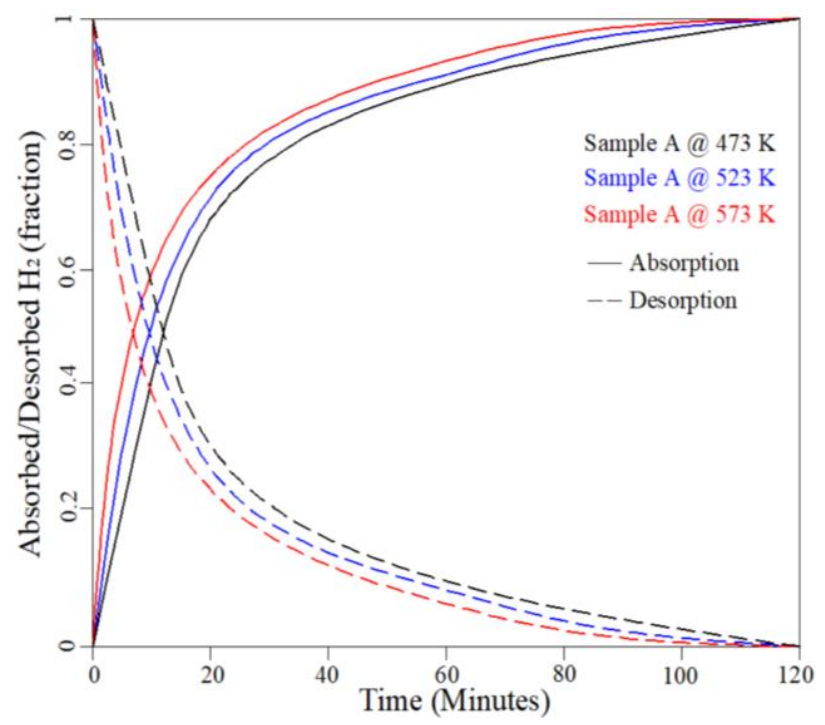

Fig. 4: Hydriding/Dehydriding rate for sample A

The change in temperature does not affect the sorption rate of sample A significantly. 
Furthermore, the dehydriding rate is relatively slower than hydriding. The low concentration of Nickel within the sample makes the physisorption insufficiently. Thus, chemisorption for hydride growth becomes slower. It also affected by low surface penetration as the sample using a large particle size. The maximum hydrogen uptake for sample A only $3.2 \mathrm{wt} \%$.

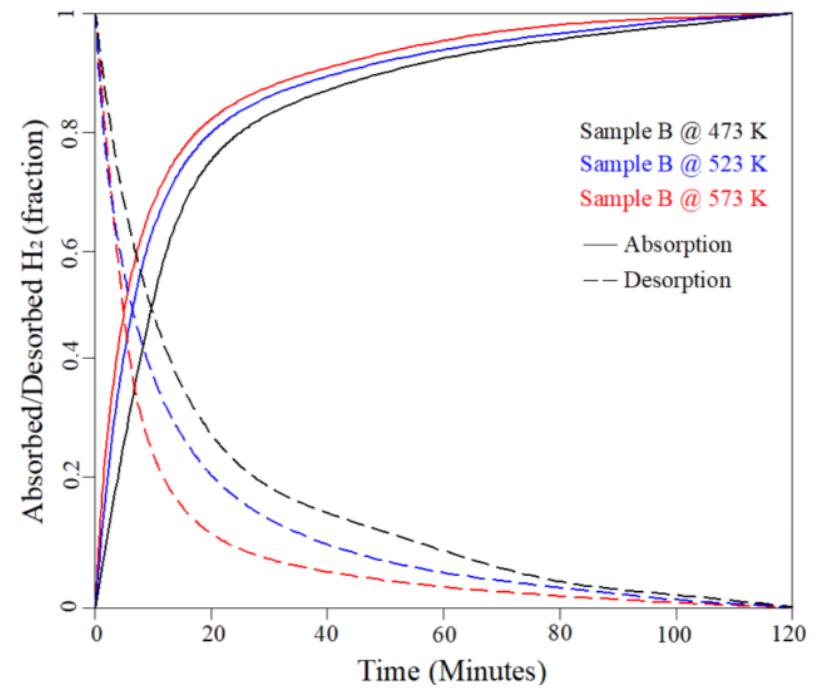

Fig. 5: Hydriding/Dehydriding rate for sample B

Compare to sample A, the sorption rate from sample B is generally better, which is indicated by faster critical sorption. The critical sorption of sample B occurs after 40 mins (Figure 5). As the sorption rate increased, the maximum hydrogen storage in sample B is higher, with a total of 3.9 $\mathrm{wt} \%$. The effect of temperature on the sorption rate is observed, especially during dehydriding. The dehydriding rate becomes faster at higher temperature $(573 \mathrm{~K})$. A higher temperature facilitates the penetration of hydrogen to the bulk metal lattice of Magnesium during hydriding, where it helps the decomposition of hydride during dehydriding. In this case, the increase in capacity is solely affected by the improvement of kinetic rate from sample B, and it is directly affected by the presence of more Nickel within the sample.
The accelerated sorption is observed from sample C. The accelerated sorption is observed both for hydriding and dehydriding. Sample C can absorb and desorb hydrogen quickly and reach more than $80 \%$ within 20 minutes (Figure 6). It leads to high hydrogen uptake and makes high hydrogen storage up to $4.2 \mathrm{wt} \%$. It is clear to state that the catalytic effect of Nickel for sample $\mathrm{C}$ is satisfactory, where it helps accelerate the hydride formation during hydriding and hydride decomposition during dehydriding [40]. It is clearly evident that adding Nickel by $16 \mathrm{wt} \%$ into magnesium hydrides will improve the kinetic rate significantly and lead to a high storage capacity.

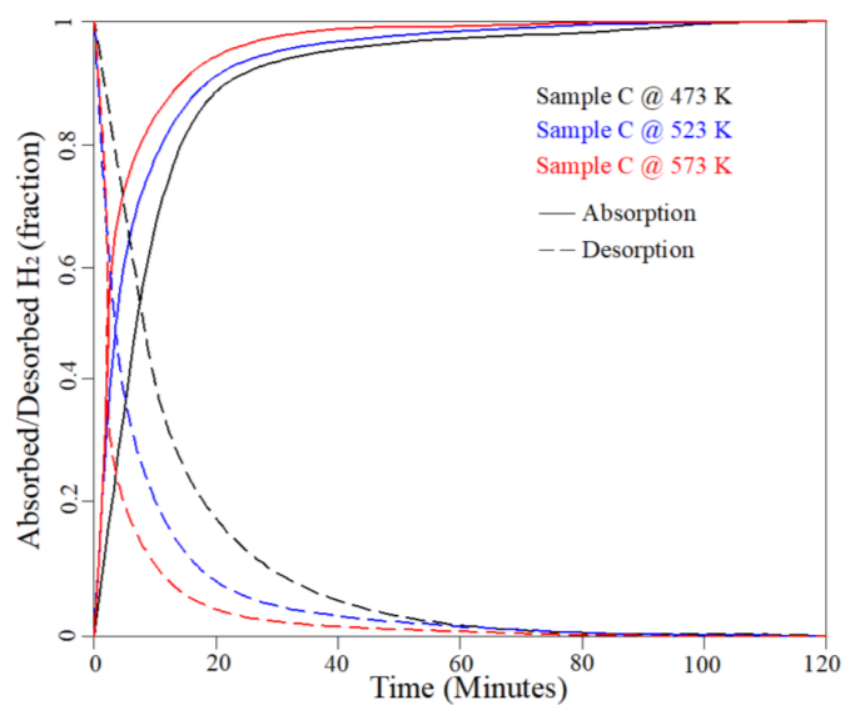

Fig. 6: Hydriding/Dehydriding rate for sample C

The hydride formation in magnesium hydride is complex and involves many steps starting from physisorption to hydride growth at the metal lattice. The physisorption can be maximized by modifying the surface structure and mechanical treatment (i.e., milling magnesium under a hydrogen atmosphere) [41,42]. The chemisorption is the most complicated step from the hydriding and dehydriding because it is related to the splitting of hydrogen molecule into atomic hydrogen till finally react with Magnesium to form hydride formation. The two essential properties of the reaction, $\Delta \mathrm{H}$ and $\Delta \mathrm{S}$, are the indicator to understand the hydride properties. 

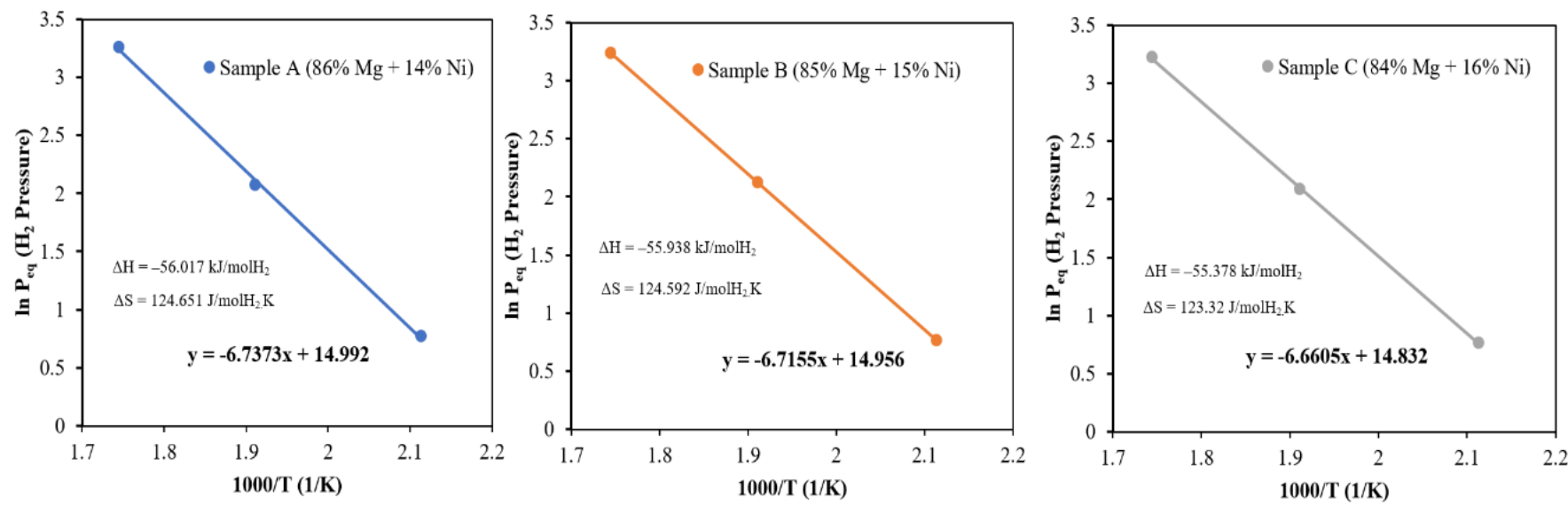

Fig. 7: Van't Hoff plot for each sample

The relation between the equilibrium pressure and temperature to the reaction properties (enthalpy dan entropy formation) can be derived from Van't Hoff plot. As seen in Figure 7, the enthalpy and entropy formation for all samples is lower than pure Magnesium. Since the sample can reach lower equilibrium pressure, it makes the enthalpy, and entropy formation decreased gradually. A lower enthalpy of formation makes the hydride formation could occur at a lower temperature, where it is the primary purpose of adding a catalyst (Nickel in this study) in magnesium hydride. As the reaction rate of sample $\mathrm{C}$ is increased significantly, then the equilibrium pressure could be occurred at lower pressure and then decreasing the reaction properties. The lowest enthalpy and entropy formation is achieved by sample $\mathrm{C}$.

\section{Discussion}

The catalytic effect of Nickel in magnesium hydride is observed, as can be seen in Fig. 1. All sample with Nickel able to absorb hydrogen faster than pure Magnesium. As the ratio of nickel increases, the sorption rate becomes quicker, where sample $\mathrm{C}$ with the highest nickel ratio shows the fastest sorption rate. Accelerated sorption rate for the sample with Nickel contributes to the elevated hydrogen uptake where it can be observed sample with more Nickel able to absorb more hydrogen under the same duration. The addition of Nickel for each sample acts differently, especially with sample $\mathrm{C}$, where the sorption started much earlier than sample A and B. The differences of the stored hydrogen between sample B and C are much higher than sample A and B. It is clear to conclude that since the amount of absorbed hydrogen varies from each sample, it shows that the increase in nickel composition does not increase the absorbed hydrogen linearly.
The releasing hydrogen during dehydrogenation is identically for each sample. As can be seen from Fig. 2, It shows the desorption for each sample where pure Magnesium still releasing hydrogen slower than the sample with Nickel. It also can be observed that the amount of desorbed hydrogen is lower than the stored hydrogen. The losses or known as hysterical losses for each sample, is varied. Sample A and B experience a higher loss with $0.02 \mathrm{wt} \%$ of stored hydrogen than sample C, only $0.01 \mathrm{wt} \%$. Another interesting result is also shown from Figure 2 regarding the effect of nickel addition on each sample, where adding $1 \mathrm{wt} \%$ of Nickel makes the desorption model differently. Compared to the hydrogenation, sample $\mathrm{A}$ and $\mathrm{C}$ release hydrogen gradually slower, and sample B can maintain sorption rate at the same duration. Sample A and C start to release hydrogen after 30 mins and 20 mins while sample B starts to release hydrogen after 20 mins, equal to the hydrogenation (red circle in Fig. 2). It can be said that the sorption behavior during hydriding and dehydriding for each sample is diverse.

According to the activation result (Fig. 3), the sorption pattern for each sample is different, and it is mainly affected by the amount of Nickel within the sample. For sample A, the amount of absorbed hydrogen from the first to the second cycle is relatively high, from $1.09 \mathrm{wt} \%$ to $1.31 \mathrm{wt} \%$. After the second cycle, the sorption has not increased significantly. It indicates that the magnesium bonding with hydrogen between the first and the second cycle is destabilized by the Nickel. The circumstance also occurred with sample $\mathrm{B}$, where the amount of absorbed hydrogen between the first and second cycle is increased significantly, which is also occurred between the third and fourth cycle. Adding Nickel into the magnesium hydride system decrease the binding energy for the hydrogen, and as the cycle goes repeatedly, it makes the sorption goes effortless. It is also proven by sample $\mathrm{C}$ where 
significant sorption occurs after the third cycle since sample $\mathrm{C}$ has more Nickel than the other sample. Besides, even though the high sorption occurred after the third cycle, the absorbed hydrogen at the first cycle is already high.

The Pressure Composition Isotherm (PCI) shows the characteristic of hydriding and dehydriding for the all samples under different temperatures. Sample A has the lowest hydrogen content by $3.2 \mathrm{wt} \%$. as shown in Figure 4, the change in temperature for sample A during PCI only increase slightly the sorption and desorption rate where the critical sorption is done after 60 mins. Sample B (Figure 5) with a higher nickel content shows a better sorption rate where the critical sorption is obtained after 40 mins. Thus, the hydrogen content for sample B able to absorb hydrogen at higher amount by $3.9 \mathrm{wt} \%$. The highest hydrogen content is achieved by sample $\mathrm{C}$ with the highest nickel ratio (16 wt\%). Sample $\mathrm{C}$ able to store hydrogen by $4.2 \mathrm{wt} \%$ and the critical sorption occurs much earlier compared to the other sample (within 20 minutes). Figure 6 is shown clearly the hydriding and dehydriding rate for sample $\mathrm{C}$ with accelerated sorption under different temperature.

The equilibrium pressure from each PCI measurement is used for predicting the Van't Hoff plot to obtain the enthalpy and entropy formation for each sample (Figure 7). The error for Van't Hoff plot can be minimized by adding more than two data measurement (i.e. equilibrium pressure) [43]. Since the PCI is done under three different temperatures, thus, the value for enthalpy and entropy formation from Van't Hoff plot is considered accurately. It also can be seen by the value obtained for each sample where the higher hydrogen content, the lower enthalpy and entropy formation for the sample. It is the reason why sample $\mathrm{C}$ has the lowest enthalpy and entropy formation by $-55.378 \mathrm{~kJ}$ and 123.32 J, respectively since the same sample also has the highest hydrogen content compared to the other. Furthermore, the deviation for Van't Hoff plot is generally occurred at low temperature formation [44]. Since the PCI is done at relatively higher temperature $(473-573 \mathrm{~K})$, the metal hydride is considered as stable formation. It also enhances the nature of magnesium hydride which has stable hydride formation, even after the addition of nickel as catalyst. The remark conclusion for this matter, the addition of nickel able to accelerates the sorption process with only slightly reduces the thermodynamic properties of magnesium hydride. Nevertheless, a higher hydrogen content with excellent hydriding and dehydriding rate for sample with nickel still desirable.

\section{Conclusion}

The study is specifically intended to observe the catalytic effect of Nickel in micron size on magnesium hydride. Nickel is a well-known catalyst for magnesium hydride to accelerate the hydriding and dehydriding process. Most of the study combined the addition of Nickel in magnesium hydride with mechanical modification and alloying, which is hard to observe the nature of catalytic effect for magnesium hydride. The result of this study is indicated that adding $16 \mathrm{wt} \%$ nickel able to improve the kinetic rate of the magnesium hydride. It also helps to decrease the enthalpy and entropy formation of the magnesium hydride. Since the process is used commercially available particle size for Nickel and Magnesium, Nickel's nature effect within the magnesium hydride is observed. Overall, adding Nickel by the range between $14-16$ wt $\%$ into magnesium hydrides will promote a better hydriding/dehydriding rate. Despite that, still, the maximum hydrogen storage is lower than pure Magnesium. However, the result of this study is still helpful for further characterization with Nickel and Magnesium to improve the overall properties of magnesium hydride to achieve a feasible level as solid-state hydrogen and thermal energy storage.

\section{References:}

[1] Ayodele B V., Khan MR, Cheng CK. Production of CO-rich hydrogen gas from methane dry reforming over $\mathrm{Co} / \mathrm{CeO} 2$ Catalyst. Bull Chem React Eng Catal 2016;11:210-9. https://doi.org/10.9767/bcrec.11.2.552.210219.

[2] Spadaro L, Palella A, Arena F. Totally-green Fuels via CO2Hydrogenation. Bull Chem React Eng Catal 2020;15:390-404. https://doi.org/10.9767/bcrec.15.2.7168.390404.

[3] Paul B, Pascal L. Simulation of a latent heat thermal energy storage for the solar airconditioning system of a net-zero energy hotel. WSEAS Trans Environ Dev 2019;15:510-26.

[4] Rahmalina D, Rahman RA, Ismail. Increasing the rating performance of paraffin up to 5000 cycles for active latent heat storage by adding high-density polyethylene to form shapestabilized phase change material. J Energy Storage 2022;46:103762. https://doi.org/10.1016/j.est.2021.103762.

[5] Rahmalina D, Adhitya DC. Improvement the Performance of Composite Pcm Paraffin-Based Incorporate With Volcanic Ash As Heat Storage for Low-Temperature. EUREKA Phys 
Eng 2022:3-11. https://doi.org/10.21303/24614262.2022.002055.

[6], et al. A multi energy storage system model based on electricity heat and hydrogen coordinated optimization for power grid flexibility. CSEE J Power Energy Syst 2019;5:266-74. https://doi.org/10.17775/cseejpes.2019.00190.

[7] Feng P, Liu Y, Ayub I, Wu Z, Yang F, Zhang Z. Optimal design methodology of metal hydride reactors for thermochemical heat storage. Energy Convers Manag 2018;174:239-47.

https://doi.org/10.1016/j.enconman.2018.08.04 3.

[8] Wen T, Zhang Z, Lin X, Li Z, Chen C, Wang Z. Research on Modeling and the Operation Strategy of a Hydrogen-Battery Hybrid Energy Storage System for Flexible Wind Farm GridConnection. IEEE Access 2020;8:79347-56. https://doi.org/10.1109/ACCESS.2020.299058 1.

[9] Xiong Y, Chen L, Zheng T, Si Y, Mei S. Electricity-Heat-Hydrogen Modeling of Hydrogen Storage System Considering OffDesign Characteristics. IEEE Access 2021;9:156768-77. https://doi.org/10.1109/ACCESS.2021.313017 5.

[10] Wang Z, Jia Y, Cai C, Chen Y, Li N, Yang M, et al. Study on the Optimal Configuration of a Wind-Solar-Battery-Fuel Cell System Based on a Regional Power Supply. IEEE Access 2021;9:47056-68. https://doi.org/10.1109/ACCESS.2021.306488 8.

[11] Ismail I, Rahman RA, Haryanto G, Pane EA. The Optimal Pitch Distance for Maximizing the Power Ratio for Savonius Turbine on Inline Configuration. Int $\mathbf{J}$ Renew Energy Res 2021;11:595-9.

[12] Ismail I, Pane EA, Haryanto G, Okviyanto T, Rahman RA. A Better Approach for Modified Bach-Type Savonius Turbine Optimization. Int Rev Aerosp Eng 2021;14:159. https://doi.org/10.15866/irease.v14i3.20612.

[13] Ismail, John J, Pane EA, Maulana R, Rahman RA, Suwandi A. Experimental evaluation for the feasibility of test chamber in the open-loop wind tunnel. WSEAS Trans Fluid Mech 2021;16:120-6. https://doi.org/10.37394/232013.2021.16.12.

[14] Mohapatra S. Hydrogen production technologies with specific reference to biomass. Int J Renew Energy Res 2012;2:416-
20. https://doi.org/10.20508/ijrer.61659.

[15] Brestovič T, Jasminská N, Lázár M, Dobáková R. Measurement of operating parameters of a hydrogen compressor using metal hydride materials. MATEC Web Conf 2018;168. https://doi.org/10.1051/matecconf/2018168060 02.

[16] Ozturk Z. The effect of surface area and dopant percentage on hydrogen storage of Pt@ac loaded activated carbon and Cu-BTC composites. Int $\mathrm{J}$ Renew Energy Res 2016;6:1007-14.

[17] Jepsen J, Milanese C, Puszkiel J, Girella A, Schiavo B, Lozano GA, et al. Fundamental material properties of the $2 \mathrm{LiBH} 4-\mathrm{MgH} 2$ reactive hydride composite for hydrogen storage: (II) Kinetic properties. Energies 2018;11. https://doi.org/10.3390/en11051170.

[18] Fang ZZ, Zhou C, Fan P, Udell KS, Bowman $\mathrm{RC}$, Vajo JJ, et al. Metal hydrides based high energy density thermal battery. J Alloys Compd 2015;645:S184-9. https://doi.org/10.1016/j.jallcom.2014.12.260.

[19] Sarbu I, Sebarchievici C, Sarbu I, Sebarchievici C. Chapter 4 - Thermal Energy Storage. 2017. https://doi.org/10.1016/B978-012-811662-3.00004-9.

[20] Elhamshri FAM, Kayfeci M. Enhancement of hydrogen charging in metal hydride-based storage systems using heat pipe. Int $\mathrm{J}$ Hydrogen Energy 2019:18927-38. https://doi.org/10.1016/j.ijhydene.2018.10.040.

[21] Suwarno S, Yartys VA. Kinetics of hydrogen absorption and desorption in titanium. Bull Chem React Eng \&amp;Amp; Catal 2017;12:312-7.

https://doi.org/10.9767/bcrec.12.3.810.312317.

[22] Mo F, Chi X, Yang S, Wu F, Song Y, Sun D, et al. Stable three-dimensional metal hydride anodes for solid-state lithium storage. Energy Storage Mater 2019;18:423-8. https://doi.org/10.1016/j.ensm.2019.01.014.

[23] Vijay Babu AR, Devunuri N, Manisha DR, Prashanthi Y, Merugu R, Ravi Teja AJR. Magnesium hydrides for hydrogen storage: A mini review. Int $J$ ChemTech Res 2014;6:3451-5.

[24] Cermak J, Kral L, Roupcova P. Improvement of hydrogen storage kinetics in ball-milled magnesium doped with antimony. Int $\mathbf{J}$ Hydrogen Energy 2017;42:6144-51. https://doi.org/10.1016/j.ijhydene.2016.11.113.

[25] Crivello JC, Dam B, Denys R V., Dornheim M, Grant DM, Huot J, et al. Review of 
magnesium hydride-based materials: development and optimisation. Appl Phys A Mater Sci Process 2016;122:1-20. https://doi.org/10.1007/s00339-016-9602-0.

[26] Gambini M, Stilo T, Vellini M, Montanari R. High temperature metal hydrides for energy systems Part A: Numerical model validation and calibration. Int $\mathrm{J}$ Hydrogen Energy 2017;42:16195-202. https://doi.org/10.1016/j.ijhydene.2017.05.062.

[27] Crivello JC, Denys R V., Dornheim M, Felderhoff M, Grant DM, Huot J, et al. Mgbased compounds for hydrogen and energy storage. Appl Phys A Mater Sci Process 2016;122:1-17. https://doi.org/10.1007/s00339-016-9601-1.

[28] Ikeda K, Nakamori Y, Orimo SI. Structural and hydriding properties of the $\mathrm{Mg}-\mathrm{Ni}-\mathrm{H}$ system with nano-and/or amorphous structures. J Metastable Nanocrystalline Mater 2005;2425:415-8.

https://doi.org/10.4028/www.scientific.net/JM NM.24-25.415.

[29] Friedlmeier G, Arakawa M, Hirai T, Akiba E. Preparation and structural, thermal and hydriding characteristics of melt-spun $\mathrm{Mg}-\mathrm{Ni}$ alloys. J Alloys Compd 1999;292:107-17. https://doi.org/10.1016/S0925-8388(99)002856.

[30] Rahmalina D, Rahman RA, Suwandi A, Ismail. The recent development on $\mathrm{MgH} 2$ system by $16 \mathrm{wt} \%$ nickel addition and particle size reduction through ball milling: A noticeable hydrogen capacity up to $5 \mathrm{wt} \%$ at low temperature and pressure. Int $\mathrm{J}$ Hydrogen Energy 2020 . https://doi.org/10.1016/j.ijhydene.2020.07.209.

[31] Malyshenko SP, Mitrokhin S V., Romanov IA. Effects of scaling in metal hydride materials for hydrogen storage and compression. J Alloys Compd 2015;645:S84-8. https://doi.org/10.1016/j.jallcom.2014.12.273.

[32] Gambini M, Stilo T, Vellini M. High temperature metal hydrides for energy systems Part B: Comparison between high and low temperature metal hydride reservoirs. Int $\mathrm{J}$ Hydrogen Energy 2017;42:16203-13. https://doi.org/10.1016/j.ijhydene.2017.03.227.

[33] Delhomme B, De Rango P, Marty P, Bacia M, Zawilski B, Raufast C, et al. Large scale magnesium hydride tank coupled with an external heat source. Int $\mathbf{J}$ Hydrogen Energy 2012;37:9103-11.

https://doi.org/10.1016/j.ijhydene.2012.03.018.

[34] Dehouche Z, Goyette J, Bose TK, Schulz R.
Moisture effect on hydrogen storage properties of nanostructured $\mathrm{MgH} 2-\mathrm{V}-\mathrm{Ti}$ composite. Int J Hydrogen Energy 2003;28:983-8. https://doi.org/10.1016/S0360-3199(02)001969.

[35] Canjura Rodriguez P, Gallandat N, Züttel A. Accurate measurement of pressurecomposition isotherms and determination of thermodynamic and kinetic parameters of metal hydrides. Int $\mathrm{J}$ Hydrogen Energy 2019;44:13583-91.

https://doi.org/10.1016/j.ijhydene.2019.03.224.

[36] Rahman RA, Suwandi A, Nurtanto M. Experimental investigation on the effect of thermophysical properties of a heat transfer fluid on pumping performance for a convective heat transfer system. J Therm Eng 2021;7:1628-39.

https://doi.org/10.14744/jten.2021.0006.

[37] Li J, Zhou C, Fang ZZ, Bowman RC, Lu J, Ren C. Isothermal hydrogenation kinetics of ball-milled nano-catalyzed magnesium hydride. Materialia 2019;5:100227. https://doi.org/10.1016/j.mtla.2019.100227.

[38] Yeetsorn R, Prapainainar C, Maiket Y. Energy efficiency evaluation assessing hydrogen production, energy storage and utilization in integrated alternative energy solutions. Int $\mathbf{J}$ Renew Energy Res 2019;9:1957-66.

[39] Sakintuna B, Lamari-Darkrim F, Hirscher M. Metal hydride materials for solid hydrogen storage: A review. Int $\mathrm{J}$ Hydrogen Energy 2007;32:1121-40.

https://doi.org/10.1016/j.ijhydene.2006.11.022.

[40] Galey B, Auroux A, Sabo-Etienne S, Dhaher S, Grellier M, Postole G. Improved hydrogen storage properties of $\mathrm{Mg} / \mathrm{MgH} 2$ thanks to the addition of nickel hydride complex precursors. Int J Hydrogen Energy 2019;44:28848-62. https://doi.org/10.1016/j.ijhydene.2019.09.127.

[41] Carraro PM, García Blanco AA, Lener G, Barrera D, Amaya-Roncancio S, Chanquía C, et al. Nanostructured carbons modified with nickel as potential novel reversible hydrogen storage materials: Effects of nickel particle size. Microporous Mesoporous Mater 2019;273:50-9. https://doi.org/10.1016/j.micromeso.2018.06.0 57.

[42] Perejón A, Sánchez-Jiménez PE, Criado JM, Pérez-Maqueda LA. Magnesium hydride for energy storage applications: The kinetics of dehydrogenation under different working conditions. J Alloys Compd 2016;681:571-9. https://doi.org/10.1016/j.jallcom.2016.04.191. 
[43] Keleti T. Errors in the evaluation of Arrhenius and van't Hoff plots. Biochem J 1983;209:277-80. https://doi.org/10.1042/bj2090277.

[44] Sluyters JH, Sluyters-Rehbach M. Deviation from van't Hoff Behavior of Solids at Low Temperature. ACS Omega 2017;2:2317-25. https://doi.org/10.1021/acsomega.7b00169.

Contribution of Individual Authors to the Creation of a Scientific Article (Ghostwriting Policy)

Dwi Rahmalina: conceptualization and methodology Reza Abdu Rahman: Investigation and writing Ismail: Supervision and validation

Sources of Funding for Research Presented in a Scientific Article or Scientific Article Itself

Not Available

\section{Creative Commons Attribution License 4.0} (Attribution 4.0 International, CC BY 4.0) This article is published under the terms of the Creative Commons Attribution License 4.0 https://creativecommons.org/licenses/by/4.0/deed.en _US 